\title{
Association between neighborhood social cohesion, awareness of chronic diseases, and participation in healthy behaviors in a community cohort
}

Andrew M. Rosenblatt ${ }^{1}$, Deidra C. Crews ${ }^{2}$, Neil R. Powe ${ }^{3,4}$, Alan B. Zonderman ${ }^{5}$, Michele K. Evans ${ }^{5}$ and Delphine S. Tuot ${ }^{3,6^{*}}$ (1)

\begin{abstract}
Background: Neighborhood social cohesion (NSC) is the network of relationships as well as the shared values and norms of residents in a neighborhood. Higher NSC has been associated with improved cardiovascular health, largely among Whites but not African Americans. In a bi-racial cohort, we aimed to study the association between NSC and chronic disease awareness and engagement in healthy self-management behaviors, two potential mechanisms by which NSC could impact cardiovascular health outcomes.

Methods: Using the Healthy Aging in Neighborhoods of Diversity Across the Lifespan Study (HANDLS), we crosssectionally examined the association between NSC and awareness of three chronic conditions (diabetes, chronic kidney disease (CKD), and hypertension) and engagement in healthy self-management behaviors including physical activity, healthy eating, and cigarette avoidance.

Results: Study participants $(n=2082$ ) had a mean age of 56.5 years; $38.7 \%$ were White and $61.4 \%$ African American. Of the participants, 26\% had diabetes, 70\% had hypertension and 20.2\% had CKD. Mean NSC was $3.3(S D=0.80)$ on a scale of 1 (lowest score) to 5 (highest score). There was no significant association between NSC and any chronic disease awareness, overall or by race. However, each higher point in mean NSC score was associated with less cigarette use and healthier eating scores, among Whites (adjusted odds ratio [aOR], 95\% confidence interval [Cl]: = 0.76, 0.61-0.94; beta coefficient $[\beta c]$ : $95 \% \mathrm{Cl}: 1.75 ; 0.55-2.97$, respectively) but not African Americans (aOR $=0.95$, $0.79-1.13 ; \beta c: 0.46,-0.48-1.39$, respectively; $P_{\text {interaction }}=0.08$ and 0.06). Among both Whites and African Americans, higher NSC scores were associated with increases in self-reported physical activity $\left(\beta c: 0.12 ; 0.08-0.16\right.$; $P_{\text {interaction }}=$ 0.40).
\end{abstract}

\footnotetext{
* Correspondence: Delphine.tuot@ucsf.edu

${ }^{3}$ Center for Vulnerable Populations at Zuckerberg San Francisco General

Hospital and Trauma Center, San Francisco, CA, USA

${ }^{6}$ Division of Nephrology, University of California, San Francisco, Zuckerberg

San Francisco General Hospital and Trauma Center, 1001 Potrero Ave.

Building 100, Room 342, San Francisco, CA 94110, USA

Full list of author information is available at the end of the article
}

(c) The Author(s). 2021 Open Access This article is licensed under a Creative Commons Attribution 4.0 International License, which permits use, sharing, adaptation, distribution and reproduction in any medium or format, as long as you give appropriate credit to the original author(s) and the source, provide a link to the Creative Commons licence, and indicate if changes were made. The images or other third party material in this article are included in the article's Creative Commons licence, unless indicated otherwise in a credit line to the material. If material is not included in the article's Creative Commons licence and your intended use is not permitted by statutory regulation or exceeds the permitted use, you will need to obtain permission directly from the copyright holder. To view a copy of this licence, visit http://creativecommons.org/licenses/by/4.0/. The Creative Commons Public Domain Dedication waiver (http://creativecommons.org/publicdomain/zero/1.0/) applies to the data made available in this article, unless otherwise stated in a credit line to the data. 
Conclusions: Community engagement and neighborhood social cohesion may be important targets for promotion of healthy behaviors and cardiovascular disease prevention. More research is needed to understand the different associations of NSC and healthy behaviors by race.

Keywords: Social cohesion, Kidney disease, CKD awareness, CKD, HANDLS, Healthy behaviors, Health disparities

\section{Background}

Kidney disease, diabetes, and hypertension affect millions of people in the United States and are associated with cardiovascular morbidity and early mortality, particularly among African Americans compared to Whites [1-5]. Consequently, cardiovascular morbidity and early mortality could be decreased with greater individual awareness of chronic diseases and engagement in risklowering behaviors, such as glycemic control among individuals with diabetes and stopping tobacco use for all individuals with chronic disease [2,6]. Nationally representative data suggest that participation in these behaviors is suboptimal [7], and large cohort studies have suggested differential engagement in healthy behaviors by socioeconomic status (SES), race, and educational attainment [8-11].

The U.S. Department of Health and Human Services has identified social cohesion as a major component to maintaining individual health [12], in part due to recent work examining the potential impact of neighborhood social cohesion (NSC) on individual health outcomes $[13,14]$. NSC is the network of relationships, shared values, and norms of residents in a neighborhood and it shares some similarities to an individual's social network [15]. It differs by accounting for value systems, degree of social interaction, and by considering the cohesion of a broader neighborhood rather than cohesion within a small group of individuals $[16,17]$.

NSC may affect the health of individuals residing close to one another through several mechanisms, such as the collective advocacy for resources, increased dissemination of health-related information, psychosocial support, and self-efficacy to engage in healthy behaviors. Recent studies have shown that stronger, denser social networks are correlated with goal attainment, general habit formation, and participation in cardiovascular risk reduction strategies $[18,19]$. NSC may similarly serve as a catalyst for healthy behaviors by improving individuals' perceived self-efficacy through the promotion of social and community ties [20], such as attendance at preventive healthcare visits, engagement in regular physical exercise, and tobacco cessation [21-24]. Personal awareness of disease or risk of developing disease is an upstream determinant to participation in healthy behaviors $[25,26]$ and might also be enhanced through strong social networks and neighborhood cohesion.
Prior U.S. studies have shown protective associations between higher NSC and some health outcomes, however results have been mixed and have differed by race. For example, data from the Chicago Health and Aging Project demonstrated that higher NSC was associated with decreased stroke mortality but not stroke incidence and was protective among Whites but not African Americans [27]. Data from the Multi-Ethic Study of Atherosclerosis suggested that higher NSC was associated with less hypertension but was not associated with kidney function decline; neither association differed by race/ethnicity $[28,29]$.

To explore the potential mechanism by which NSC could impact cardiovascular health events, we aimed to examine whether NSC was associated with awareness of three common chronic diseases that are risk factors for cardiovascular disease (chronic kidney disease, hypertension, diabetes) and engagement in healthy selfmanagement behaviors. Since previous data suggested racial differences in the association between NSC and health outcomes, we examined these associations by race, leveraging a bi-racial cohort of socioeconomically diverse, community-dwelling adults.

\section{Methods}

\section{Study design and participants}

We conducted a cross-sectional study examining the relationship between individual perception of neighborhood social cohesion, awareness of health conditions, and participation in healthy behaviors among individuals who participated in the prospective longitudinal Healthy Aging in Neighborhoods of Diversity Across the Life Span (HANDLS) study, taking place between 2013 and 2017. To identify the interaction of race and socioeconomic status on the development of cardiovascular and cerebrovascular health disparities, the HANDLS study recruited community-dwelling African Americans and Whites aged 30-64 years from an area probability sample of 13 neighborhoods representing contiguous U.S. census tracts in Baltimore City. Based on 2000 census data, these neighborhoods were thought to yield sufficient individuals to recruit a minimum of 30 participants per cell defined by race (African American, White) socioeconomic status (above and below 125\% of the 2004 Health and Human Services Poverty guidelines), age (seven 5-year age groups) and sex (male, female), necessary to detect a difference in cardiovascular outcomes 
with $80 \%$ power after 20 years. HANDLS participants were recruited in two phases: household recruitment and interview followed by examination in medical research vehicles belonging to the study. Detailed methods for recruitment in HANDLS have been reported elsewhere [30].

Overall, 3720 individuals participated in a Wave 1 (baseline) study visit between August 2004 and March 2009. Wave 4 visits occurred between September 2013 and September 2017 and consisted of in-person health examination, a telephonic dietary recall, renal function assessment, and optional participation in a telephonebased survey. Nearly $58 \%$ of Wave 1 participants $(n=$ 2171/3720) had a Wave 4 visit, during which most data were collected for this ancillary study, including the primary predictor. This study population excluded individuals missing serum creatinine and urine albuminuria values $(n=71)$, and those with an estimated glomerular filtration rate $($ eGFR $)<15 \mathrm{ml} / \mathrm{min} / 1.73 \mathrm{~m}^{2}(n=18)$ at Wave 4, for a final study population was 2082. National Institutes of Health Institutional Review Board (\#09AGN248), approved the study protocol, as did the University of California, San Francisco Institutional Review Board (\#10-02885). All participants provided written, informed consent to participate.

\section{Data collection and definitions}

The primary explanatory variable was individual perception of neighborhood social cohesion, based on a validated questionnaire of 5 questions asking about unique neighborhood characteristics [17]. Individuals were asked to agree or disagree with the following statements using a 1-5 Likert scale in which 1 represented strong disagreement and 5 represented strong agreement: (1) "People in my neighborhood are willing to help their neighbors;" (2) "I live in a close-knit neighborhood;" (3) "People in my neighborhood can be trusted," (4) "People in my neighborhood generally do not get along with each other;" and (5) People in my neighborhood do not share the same values." Consistent with prior research, a composite neighborhood social cohesion score was calculated as the mean of the 5 items with items (4) and (5) reverse coded, with higher values representing more agreement that there was social cohesion [31, 32].

Awareness outcomes included awareness of kidney disease, diabetes, and hypertension, defined by accurate self-report of each of these chronic conditions during the Wave 4 health questionnaire compared to study measures of eGFR, fasting glucose/use of antidiabetic medications, and $\mathrm{BP} /$ use of anti-hypertensive medications [33]. Behavioral outcomes were defined by selfreported participation in healthy behaviors: no cigarette use, higher physical activity defined by the Baecke physical activity questionnaire [34], and heathy eating defined by the 2010 Healthy Eating Index [35].

Covariates included self-reported demographic information (age, sex, race, educational attainment, health insurance, having a regular healthcare provider, annual household income, and co-morbid conditions) obtained during Wave 1. Health literacy was measured with the hort Test of Functional Health Literacy in Adults (STOFHLA) using a cutoff score of 60 to differentiate between individuals with adequate vs. inadequate literacy levels [36]. Physical exam measures included blood pressure, height, and weight. Each participant underwent sitting and standing blood pressure measurements on each arm using the brachial artery auscultation method with an inflatable cuff of appropriate size. Laboratory measures included serum creatinine, urine microalbumin, serum glycated hemoglobin, and fasting glucose. Diabetes was defined by a fasting glucose $>126 \mathrm{ml} / \mathrm{dl}$ or use of an antidiabetic medication. Hypertension was defined by an uncontrolled measured BP defined by an average seated study systolic blood pressure $>140 \mathrm{mmHg}$ or an average seated study diastolic $\mathrm{BP}>90 \mathrm{mmHg}$ or use of an anti-hypertensive medication. CKD was defined by single values of eGFR $<60 \mathrm{ml} / \mathrm{min} / 1.73 \mathrm{~m}^{2}$ calculated by the Chronic Kidney Disease Epidemiology Collaboration (CKD-EPI) equation or the presence a urine microalbumin-to-creatinine ratio (UACR) $>30 \mathrm{mg} / \mathrm{g}$ [37, 38].

\section{Statistical analysis}

Characteristics of participants were compared by tertile of perceived social cohesion using $X^{2}$ and ANOVA tests as appropriate. Multivariable logistic regression models were used to determine the presence, direction, strength and independence of an association between mean social cohesion score (modeled as a continuous variable) and awareness of each chronic condition (CKD, diabetes, hypertension) and cigarette use (all binary variables). Multivariable linear regression models were used to determine the association of mean social cohesion score with physical activity and healthy eating scores modeled as continuous variables. All models represented complete case analyses and included variables that were either determined a priori based on prior literature or statistically associated with tertile of social cohesion. Model 1 included age, sex, and race. Model 2 further adjusted for additional demographic variables (educational attainment, health insurance status, and having a regular healthcare provider). Model 3 further adjusted for clinical variables (diabetes status, hypertension status, eGFR, and UACR) when appropriate (i.e., models examining diabetes awareness did not include diabetes status; models examining hypertension awareness did not include hypertension status). Interaction between race and 
neighborhood social cohesion was assessed in each fully adjusted model. All statistical analyses were performed using STATA software, Version 14.2 (StataCorp, College Station, Texas, USA).

\section{Results}

\section{Cohort characteristics}

Among the study population of 2082 individuals, mean (SD) age was 56.5 (9.1) years, $40.9 \%$ were men, 38.7\% were White, and $61.4 \%$ were African American. Mean NSC for the entire cohort was $3.3(\mathrm{SD}=0.80)$ with a mean score in the first NSC tertile of 2.55 (standard deviation $[\mathrm{SD}]=0.51)$, a mean score of $3.40(\mathrm{SD}=0.16)$ in the second NSC tertile, and a mean score of 4.23 (SD = 0.38 ) in the third NSC tertile. Among the entire cohort, $32.3 \%$ did not complete their high school education and $12.7 \%$ had low health literacy, percentages that did not differ by social cohesion tertile. Approximately 39\% of the cohort lived below the $125 \%$ federal poverty level with fewer individuals living below the poverty level among those who self-reported higher social cohesion $(p<0.001)$. Nearly $65 \%$ of participants reported having health insurance and $68.8 \%$ cited a regular source of health care, with higher percentages of individuals reporting either characteristic with increasing social cohesion score $(p=0.002$ and $p=0.04$, respectively). Of the overall cohort, $26.3 \%$ were diabetic and $70 \%$ had hypertension. Approximately $58.9 \%$ of individuals had CKD stage 3 or 4 and $13.9 \%$ had urine albuminuria levels > $30 \mathrm{mg} / \mathrm{g}$ of creatinine (Table 1).

Wave 4 participants were generally similar to those who completed the baseline study visit. However, Wave 4 participants were more likely to be female compared to those participants who were lost to follow-up (58.6\% vs. $49.2 \%, p<0.01)$ and more likely to be African American $(61.1 \%$ vs. $56.3 \%, p=0.003)$. Education, poverty status and insurance were not different among the two groups (data not shown, $p>0.05$ ). Of the Wave 4 study population, 1918 individuals answered questions about social cohesion. While individuals who did not complete the NSC questionnaire were generally similar to those who did, individuals missing NSC scores were less likely to be a college graduate, more likely to have low health literacy, and more likely to have diagnosed hypertension and diabetes. (Supplemental Table).

\section{Neighborhood social cohesion and awareness of chronic disease}

Overall, $18.7 \%$ (86/460) of individuals with CKD were aware of their disease. Among those aware of their CKD, mean NSC score was $3.32(\mathrm{SD}=0.73)$ with similar prevalence of awareness by tertile of neighborhood social cohesion (Fig. 1). Nearly $90 \%$ of individuals with diabetes $(89.7 \%, 330 / 368)$ were aware of their condition. Of those aware, mean NSC score was $3.20(\mathrm{SD}=0.78)$. A similar, high percentage of individuals $(90.7 \%, n=936 / 1032)$ reported awareness of hypertension with a similar distribution of awareness by neighborhood social cohesion scores; mean NSC among those aware was 3.28 ( $\mathrm{SD}=$ 0.79).

Using multivariable logistic regression, increasing mean social cohesion score was not significantly associated with awareness of CKD (adjusted odds ratio $[\mathrm{aOR}]=1.13 ; 95 \%$ Confidence $\quad$ Interval $=0.81,1.56$ ), awareness of diabetes $(\mathrm{aOR}=0.94 ; 0.57-1.55)$ or awareness of hypertension $(\mathrm{aOR}=1.15 ; 0.87-1.51)$. None of the associations between NSC and awareness differed by race $\left(\mathrm{P}_{\text {interaction NSC } \mathrm{x} \text { race }}>0.10\right)$.

\section{Neighborhood social cohesion and healthy behaviors}

Neighborhood social cohesion scores were independently associated with many healthy lifestyle habits and often differed by race (Table 2). For example, there were $13.1 \%$ decreased odds of cigarette use with every onepoint gain in self-reported mean social cohesion score $(\mathrm{aOR}=0.87 ; 0.76,0.99)$, an association largely driven among White participants $\left(P_{\text {interaction NSC } x \text { race }}=0.08\right)$. Among Whites, odds of cigarette use were $24 \%$ lower with each higher point in NSC $(\mathrm{aOR}=0.76 ; 0.61-0.94)$ while there was no association between cigarette use and NSC score among African Americans $(\mathrm{aOR}=0.95$; 0.791.13). Similarly, every one-point increase in mean NSC score was associated with an increase in healthy eating engagement according to the Healthy Eating Index, (beta coefficient $[\beta c]$ : $1.08 ; 95 \%$ Confidence Interval $=0.34$ $1.82)$, largely driven by White participants $\left(\mathrm{P}_{\text {interaction }}\right.$ NSC $\times$ race $=0.06$ ). Among Whites, every one-point increase in mean NSC was associated with an increase of healthy eating engagement score $(\beta c$ : $1.75 ; 0.55-2.97)$ while the association was not statistically significant among African Americans ( $\beta$ c: $0.46 ;-0.48-1.39)$. Higher neighborhood social cohesion scores were associated with increased physical activity $(\beta \mathrm{c}$ : $0.12 ; 0.08-0.16)$ without any difference by race $\left(P_{\text {interaction NSC } \times \text { race }}=\right.$ $0.40)$.

Other sociodemographic characteristics were also independently associated with participation in healthy behaviors. As depicted in Table 2, younger age was associated with higher odds of cigarette use $(\mathrm{aOR}=0.97$; $0.96-0.98)$ and less physical activity ( $\beta c:-0.005 ;-0.01-$ $0.001)$ whereas older age was associated with higher report of healthy eating habits ( $\beta$ c: $0.23 ; 0.12-0.31$ ). Having a greater than high school education was uniformly helpful, associated with lesser odds of cigarette use $(\mathrm{aOR}=0.58 ; 0.47-0.73)$, greater healthy eating $(\beta \mathrm{c}: 3.23$; $1.95-4.51)$, and more physical activity ( $\beta \mathrm{c}$ : $0.11 ; 0.04-$ 0.19 ). Poverty, on the other hand, was associated with greater odds of cigarette use $(\mathrm{aOR}=1.51 ; 1.21-1.87)$ and 
Table 1 Characteristics of the study population, by tertile of social cohesion

\begin{tabular}{|c|c|c|c|c|c|}
\hline Characteristics & $N=2082$ & $\begin{array}{l}\text { Tertile } 1 \text { Social Cohesion } \\
\text { Score } \\
\text { range: } 1 .-0-3.0 \\
N=792\end{array}$ & $\begin{array}{l}\text { Tertile } 2 \text { Social Cohesion } \\
\text { Score } \\
\text { range: } 3.2-3.6 \\
N=565\end{array}$ & $\begin{array}{l}\text { Tertile } 3 \text { Social Cohesion } \\
\text { score } \\
\text { range: } 3.7-5.0 \\
N=561\end{array}$ & $P$ Value \\
\hline Overall Mean NSC (SD) & $3.29(0.80)$ & $2.55(0.51)$ & $3.39(0.16)$ & $4.24(0.38)$ & \\
\hline Age, mean (SD) & $56.5(9.1)$ & $55.8(9.0)$ & $56.9(9.0)$ & $56.9(9.4)$ & 0.03 \\
\hline Female, N (\%) & $1133(59.1)$ & $492(62.1)$ & $300(53.1)$ & $341(60.8)$ & 0.002 \\
\hline Race/ethnicity, N (\%) & & & & & $<0.001$ \\
\hline White & $792(38.7)$ & $325(41.0)$ & $183(32.3)$ & $241(43.0)$ & \\
\hline African American & $1278(61.4)$ & $467(59.0)$ & $382(67.6)$ & $320(57.0)$ & \\
\hline Educational attainment, N (\%) & & & & & $<0.001$ \\
\hline$<$ High school & $604(32.3)$ & $283(36.7)$ & $197(35.6)$ & $124(22.6)$ & \\
\hline High school graduate & $1023(54.6)$ & $418(54.2)$ & $300(54.3)$ & $305(55.7)$ & \\
\hline College graduate & $245(13.1)$ & $70(9.1)$ & $56(10.1)$ & $119(21.7)$ & \\
\hline $\begin{array}{l}\text { Poverty }(<125 \% \text { poverty level), } \\
\text { N (\%) }\end{array}$ & $755(39.4)$ & $356(45.0)$ & $228(40.4)$ & $171(30.5)$ & $<0.001$ \\
\hline Low health literacy, N (\%) & $264(12.7)$ & $99(17.2)$ & $79(18.3)$ & $57(12.7)$ & 0.05 \\
\hline Has health insurance, N (\%) & $1351(64.9)$ & $490(61.9)$ & $359(63.5)$ & $398(70.9)$ & 0.002 \\
\hline $\begin{array}{l}\text { Regular source of healthcare, N } \\
(\%)\end{array}$ & $1290(68.8)$ & $477(61.7)$ & $343(62.0)$ & $373(68.0)$ & 0.04 \\
\hline Diagnosed diabetes, N (\%) & $504(26.3)$ & $216(27.3)$ & $121(21.4)$ & $114(20.4)$ & 0.005 \\
\hline Diagnosed hypertension, N (\%) & $1340(70.0)$ & $510(64.4)$ & $371(65.8)$ & $344(61.5)$ & 0.32 \\
\hline BMI, mean (SD) & $30.9(7.9)$ & $31.2(8.1)$ & $30.6(7.2)$ & $30.7(7.9)$ & 0.36 \\
\hline Hemoglobin A1C, mean (SD) & $6.2(1.3)$ & $6.2(1.3)$ & $6.2(1.2)$ & $6.1(1.3)$ & 0.36 \\
\hline $\mathrm{SBP}(\mathrm{mmHg})$, mean $(\mathrm{SD})$ & $117.3(20.3)$ & $117.4(19.8)$ & $117.7(19.3)$ & $116.3(21.8)$ & 0.39 \\
\hline $\mathrm{DBP}(\mathrm{mmHg})$, mean (SD) & $65.6(11.1)$ & $65.7(10.6)$ & $65.8(10.4)$ & $64.7(12.2)$ & 0.15 \\
\hline $\begin{array}{l}\text { eGFR }\left(\mathrm{ml} / \mathrm{min} / 1.73 \mathrm{~m}^{2}\right) \text {, mean } \\
\text { (SD) }\end{array}$ & $80.8(18.5)$ & $81.0(18.1)$ & $80.4(18.3)$ & $81.4(18.7)$ & 0.62 \\
\hline $\begin{array}{l}\text { eGFR }<60 \mathrm{~min} / \mathrm{min} / 1.73 \mathrm{~m}^{2}, \mathrm{~N} \\
\text { (\%) }\end{array}$ & $271(58.9)$ & $113(61.4)$ & $85(58.6)$ & $73(55.7)$ & 0.39 \\
\hline $\begin{array}{l}\text { Albuminuria }(\mathrm{mg} / \mathrm{g}) \text {, median } \\
\text { (IQR) }\end{array}$ & $\begin{array}{l}5.5(3.5 \\
12.8)\end{array}$ & $5.5(3.5,12.6)$ & $5.4(3.5,13.9)$ & $5.1(3.2,11.3)$ & 0.42 \\
\hline Albuminuria > 30 mg/g, N (\%) & $263(13.9)$ & $110(14.1)$ & $83(14.8)$ & $70(12.7)$ & 0.59 \\
\hline
\end{tabular}

${ }^{a}$ Among the entire cohort, $n=2082$ for all rows except: Age: $(n=1917)$, Educational attainment (total $\left.n=2034\right)$, Health literacy (total $\left.n=1558\right)$, Regular source of healthcare (total $n=2036$ ); Diagnosed hypertension (total $n=207$ ), Diagnosed diabetes (total $n=2081$ ), BMI ( $n=1903$ ), Hemoglobin A1c (total $n=1893$ ), SBP and DBP (total $n=1910)$, eGFR $(n=1904)$, albuminuria total $(n=1893)$. Approximately $91.7 \%$ of the population $(n=1918)$ answered questions about social cohesion

non-statistically associated with less healthy eating $(\beta \mathrm{c}$ : $-2.45 ;-3.68--1.23)$ and less physical activity $(\beta \mathrm{c}:-$ $0.08 ;-0.15-0.01)$. These values are stratified by race in Table 2.

\section{Discussion}

We examined the relationship between NSC and two potential mechanisms by which it could affect cardiovascular outcomes: awareness of chronic disease and engagement in healthy self-management behaviors. We found no association between NSC and individual awareness of chronic disease, overall or by race, which is a novel contribution to the literature on this topic.
Consistent with data from prior studies, we found that higher neighborhood social cohesion scores were associated with greater engagement in healthy selfmanagement behaviors among Whites but less so among African Americans.

Successful habit formation is aided by the presence of a significant social support network that can encourage adherence to or abstinence from a habit or behavior whereby individuals may observe the consequences of engaging or not engaging in a behavior by their peers [39]. According to social cognitive theory, individuals with high self-efficacy expectancies-the belief in one's capacity to achieve one's goals-are healthier, more 


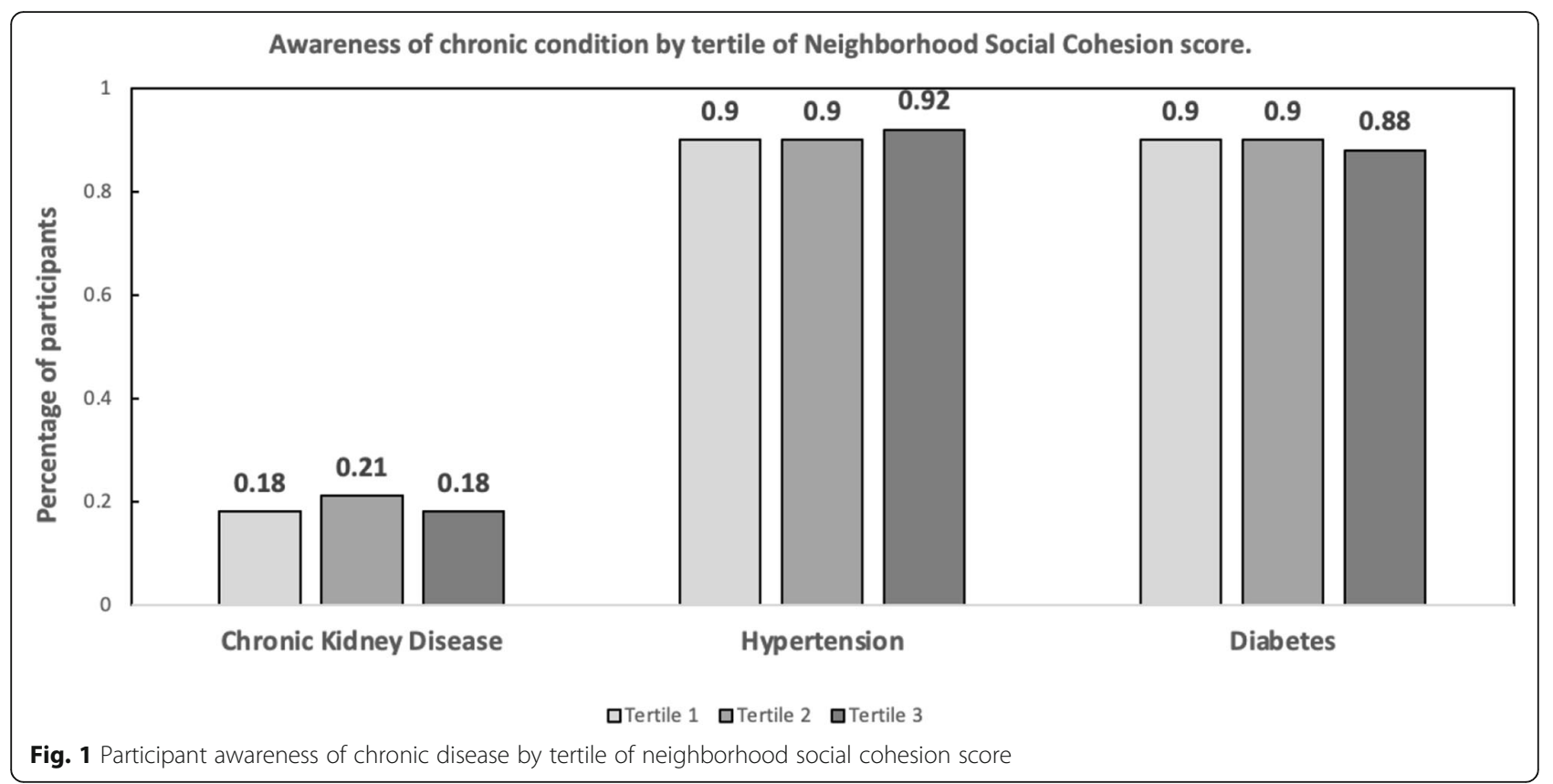

Table 2 Characteristics associated with healthy behaviors (cigarette use, healthy eating, physical activity), stratified by race. Adjusted odds ratios (aOR) and 95\% Confidence Intervals (Cl) are presented for the logistic model; beta coefficients ( $\beta \mathrm{C})$ and $95 \% \mathrm{Cl}$ are presented for linear models

\begin{tabular}{|c|c|c|c|c|c|c|}
\hline \multirow[t]{2}{*}{ Characteristics } & \multicolumn{2}{|l|}{ Cigarette use } & \multicolumn{2}{|l|}{ Healthy eating } & \multicolumn{2}{|l|}{ Physical activity } \\
\hline & $\begin{array}{l}\text { African } \\
\text { Americans aOR } \\
(95 \% \mathrm{Cl})\end{array}$ & $\begin{array}{l}\text { Whites aOR } \\
(95 \% \mathrm{Cl})\end{array}$ & $\begin{array}{l}\text { African Americans } \\
\beta \mathrm{C}(95 \% \mathrm{Cl})\end{array}$ & $\begin{array}{l}\text { Whites } \beta c \\
(95 \% \mathrm{Cl})\end{array}$ & $\begin{array}{l}\text { African Americans } \\
\beta c(95 \% \mathrm{Cl})\end{array}$ & $\begin{array}{l}\text { Whites } \beta c \\
(95 \% \mathrm{Cl})\end{array}$ \\
\hline $\begin{array}{l}\text { Mean neighborhood } \\
\text { social cohesion score }\end{array}$ & $\begin{array}{l}0.95 \\
(0.80,1.14)\end{array}$ & $\begin{array}{l}0.76 \\
(0.61,0.94)\end{array}$ & $\begin{array}{l}0.46 \\
(-0.48,1.39)\end{array}$ & $\begin{array}{l}1.75 \\
(0.53,2.97)\end{array}$ & $\begin{array}{l}0.09 \\
(0.04,0.15)\end{array}$ & $\begin{array}{l}0.14 \\
(0.08,0.21)\end{array}$ \\
\hline $\begin{array}{l}\text { Age } \\
\text { (per year) }\end{array}$ & $\begin{array}{l}0.97 \\
(0.95,0.98)\end{array}$ & $\begin{array}{l}0.98 \\
(0.95,0.99)\end{array}$ & $\begin{array}{l}0.28 \\
(0.19,0.37)\end{array}$ & $\begin{array}{l}0.15 \\
(0.01,0.28)\end{array}$ & $\begin{array}{l}-0.07 \\
(-0.01,-0.002)\end{array}$ & $\begin{array}{l}-0.003 \\
(-0.01,0.004)\end{array}$ \\
\hline Female sex & $\begin{array}{l}0.67 \\
(0.51,0.89)\end{array}$ & $\begin{array}{l}1.24 \\
(0.87,1.78)\end{array}$ & $\begin{array}{l}0.59 \\
(-0.85,2.05)\end{array}$ & $\begin{array}{l}2.71 \\
(0.62,4.80)\end{array}$ & $\begin{array}{l}-0.12 \\
(-0.19,-0.04)\end{array}$ & $\begin{array}{l}-0.17 \\
(-0.28,-0.05)\end{array}$ \\
\hline $\begin{array}{l}\text { High school graduate } \\
\text { or above }\end{array}$ & $\begin{array}{l}0.62 \\
(0.47,0.84)\end{array}$ & $\begin{array}{l}1.54 \\
(0.37,0.78)\end{array}$ & $\begin{array}{l}2.78 \\
(1.24,4.32)\end{array}$ & $\begin{array}{l}4.13 \\
(1.86,6.39)\end{array}$ & $\begin{array}{l}0.07 \\
(-0.01,0.16)\end{array}$ & $\begin{array}{l}0.16 \\
(0.04,0.29)\end{array}$ \\
\hline $\begin{array}{l}\text { Poverty } \\
(<125 \% \\
\text { federal poverty level) }\end{array}$ & $\begin{array}{l}1.53 \\
(1.17,2.02)\end{array}$ & $\begin{array}{l}1.45 \\
(0.99,2.01)\end{array}$ & $\begin{array}{l}-1.88 \\
(-3.31,-0.44)\end{array}$ & $\begin{array}{l}-3.44 \\
(-5.69,-1.18)\end{array}$ & $\begin{array}{l}-0.03 \\
(-0.11,0.05)\end{array}$ & $\begin{array}{l}-0.17 \\
(-0.29,-0.04)\end{array}$ \\
\hline Insurance status & $\begin{array}{l}0.82 \\
(0.59,1.13)\end{array}$ & $\begin{array}{l}0.82 \\
(0.52,1.26)\end{array}$ & $\begin{array}{l}1.49 \\
(-0.27,3.26)\end{array}$ & $\begin{array}{l}1.67 \\
(-1.03,4.37)\end{array}$ & $\begin{array}{l}-0.06 \\
(-0.16,0.04)\end{array}$ & $\begin{array}{l}-0.03 \\
(-0.18,0.12)\end{array}$ \\
\hline $\begin{array}{l}\text { Regular provider } \\
\text { for healthcare }\end{array}$ & $\begin{array}{l}0.72 \\
(0.52,1.00)\end{array}$ & $\begin{array}{l}0.55 \\
(0.36,0.85)\end{array}$ & $\begin{array}{l}1.19 \\
(0.87,1.61)\end{array}$ & $\begin{array}{l}1.99 \\
(-0.68,4.66)\end{array}$ & $\begin{array}{l}-0.003 \\
(-0.10,0.09)\end{array}$ & $\begin{array}{l}0.12 \\
(-0.03,0.27)\end{array}$ \\
\hline Diabetes diagnosis & $\begin{array}{l}0.70 \\
(0.51,0.98)\end{array}$ & $\begin{array}{l}1.13 \\
(0.72,1.76)\end{array}$ & $\begin{array}{l}1.37 \\
(-0.31,3.05)\end{array}$ & $\begin{array}{l}2.14 \\
(-0.47,4.74)\end{array}$ & $\begin{array}{l}-0.17 \\
(-0.26,-0.08)\end{array}$ & $\begin{array}{l}-0.25 \\
(-0.39,-0.10)\end{array}$ \\
\hline Hypertension diagnosis & $\begin{array}{l}1.09 \\
(0.80,1.49)\end{array}$ & $\begin{array}{l}0.92 \\
(0.63,1.34)\end{array}$ & $\begin{array}{l}-0.80 \\
(-2.44,0.83)\end{array}$ & $\begin{array}{l}-1.49 \\
(-3.69,0.71)\end{array}$ & $\begin{array}{l}-0.17 \\
(-0.26,-0.08)\end{array}$ & $\begin{array}{l}-0.26 \\
(-0.38,-0.14)\end{array}$ \\
\hline $\begin{array}{l}\text { eGFR } \\
\left.\text { (per } \mathrm{ml} / \mathrm{min} / 1.73 \mathrm{~m}^{2}\right)\end{array}$ & $\begin{array}{l}1.00 \\
(1.00,1.01)\end{array}$ & $\begin{array}{l}1.01 \\
(0.99,1.02)\end{array}$ & $\begin{array}{l}0.04 \\
(-0.006,0.08)\end{array}$ & $\begin{array}{l}-0.02 \\
(-0.09,0.05)\end{array}$ & $\begin{array}{l}0.0009 \\
(-0.001,0.003)\end{array}$ & $\begin{array}{l}0.005 \\
(0.001,0.009)\end{array}$ \\
\hline $\begin{array}{l}\text { uACR } \\
\text { (per mg/g) }\end{array}$ & $\begin{array}{l}0.99 \\
(0.99,1.00)\end{array}$ & $\begin{array}{l}1.00 \\
(1.00,1.00)\end{array}$ & $\begin{array}{l}-0.0005 \\
(-0.004,0.003)\end{array}$ & $\begin{array}{l}-0.0005 \\
(-0.004,0.003)\end{array}$ & $\begin{array}{l}-6 \times 10^{-5} \\
(-0.0002,0.00008)\end{array}$ & $\begin{array}{l}-2.27 \times 10^{-6} \\
(-0.0001,0.0001)\end{array}$ \\
\hline
\end{tabular}

Models are adjusted for all covariates listed

eGFR estimated glomerular filtration rate, UACR urine albumin:creatinine ratio 
effective at engaging in healthy lifestyles, and generally more successful than those with low self-efficacy expectancies [40]. High self-efficacy can be developed through a support network of trusted or respected peers [20]. If higher levels of neighborhood social cohesion provide a stronger social network, then social cognitive theory suggests that an individual would be likelier to engage in healthy behaviors in a highly socially cohesive environment [41]. This would allow individuals to collectively advocate for resources and knowledge, potentially increase individual self-efficacy, and have greater exposure to the positive and negative consequences of engaging or disregarding healthy self-management behaviors.

Our results suggesting that higher NSC is associated with higher individual engagement in self-management behaviors is consistent with prior work demonstrating greater receipt of preventive health measures, such as the influenza vaccine, cholesterol testing, and age appropriate cancer screening with higher reported NSC [24, $41,42]$. These results have implications for the encouragement of behaviors which may prevent chronic disease onset or progression. In addition to the traditional channel of encouraging healthy self-management behaviors through a primary care provider and the primary care medical home, medical professionals and community leaders could improve public health by sponsoring and organizing social community engagement initiatives which increase the social cohesion of the neighborhood, even if they are not directly related to health, such as neighborhood walks and park cleanups [43]. These gatherings could also incorporate more traditional public health initiatives such as disease-screening fairs and healthy cooking workshops. Many efficacious healthrelated community initiatives have enhanced disease detection and awareness [44-47], but none to our knowledge have been evaluated for their impact on social cohesion, providing another method to examine the public health impact of such programs.

The differences in association between NSC and tobacco use and healthy eating by race have been shown previously $[48,49]$, and is consistent with known racial differences in cardiovascular outcomes but merits further investigation. One possible explanation is that social cohesion can be a detriment as well as a benefit. While we did not have data on neighborhood composition, prior work suggested that Baltimore's neighborhoods have a high degree of social racial segregation [50]. If study participants' neighborhoods and social circles were relatively homogenous in their racial composition and healthy behavior engagement was higher among Whites compared to African Americans, increased social cohesion would promote healthier behaviors among one group and not the other. This is consistent with known African American-White inequalities in hypertension, diabetes, and obesity in areas with more racial segregation [10, 51]. Similarly, it may also be that Whites had greater access to resources that would allow them to choose healthier diets and to quit smoking if encouraged by their strong neighborhood ties, while African Americans may have wanted to make the same choices when encouraged but could not realize them. However, we did not see these differences extended to physical activity, which would be expected. Future work should examine the role of racial segregation among residential neighborhoods with engagement in healthy self-management behaviors.

We did not find an association between NSC and participants' awareness of their own chronic disease. We thought that awareness of disease might be an inciting factor in behavior change and that social cohesion might work through this mechanism. Active participation in healthy self-management behaviors is likely more impacted by self-efficacy and social networks than knowledge about one's own disease [52, 53]. This hypothesis could explain why other studies have found lower prevalence of hypertension [54] and type 2 diabetes [55] in neighborhoods with high social cohesion, meriting further investigation of the interaction between social cohesion and chronic disease.

Our findings must be appreciated within the limitations of this study. First, causality cannot be inferred because of the cross-sectional nature of this study. Also, reverse causality (i.e. higher participation in healthy behaviors leading to increased self-reported NSC) cannot be ruled out, and there may be residual confounding, as with all observational studies. Second, CKD status was defined by single measurements of eGFR or albuminuria, potentially leading to misclassification. Third, participation in healthy behaviors was self-reported which may have introduced subjectivity to the reports, potentially through social desirability bias, which may differ by race, though definitive data are lacking [56]. These inaccuracies could also be differential with respect to NSC, in that social biases may have a stronger effect where there is greater NSC. Finally, we lacked data on the racial composition of individual neighborhoods in this study, so results may not be generalizable to non-urban populations across the United States. Selection bias resulting from differences in who agrees to participate and remain in a longitudinal cohort study may limit generalizability.

\section{Conlcusions}

In summary, our results show a significant association between higher NSC scores and increased participation in healthy self-management behaviors, particularly among Whites, but no association between NSC and disease awareness. These findings suggest that individual engagement in healthy behaviors may be a mediator in 
the association between high NSC and fewer adverse health outcomes for individuals residing in neighborhoods where healthy behaviors are widely practiced. While these racial differences merit greater study, our results indicate that targeting community engagement and bolstering the social cohesion of a neighborhood could have significant benefits for communities' public health.

\section{Abbreviations}

NSC: Neighborhood social cohesion; CKD: Chronic kidney disease; SES: Socioeconomic status; HANDLS: Healthy Aging in Neighborhoods of Diversity Across the Life Span; eGFR: estimated glomerular filtration rate; TOFHLA: Test of Functional Health Literacy in Adults; BP: Blood pressure; CKD-EPI: Chronic Kidney Disease Epidemiology Collaboration; UACR: Urine albumin-to-creatinine ratio; aOR: Ajusted odds ratio

\section{Supplementary Information}

The online version contains supplementary material available at https://doi. org/10.1186/s12889-021-11633-8.

Additional file 1: Supplemental Table. Characteristics of the study population, by missingness of NSC.

\section{Acknowledgements}

We thank the participants of the HANDLS cohort study.

\section{Authors' contributions}

Research idea and study design: AMR, DST; data acquisition: ABZ, MKE; data analysis/interpretation: AMR, DST, NRP, DCC; statistical analysis: DST; supervision or mentorship: DST. Each author contributed important intellectual content during manuscript drafting or revision and accepts accountability for the overall work by ensuring that questions pertaining to the accuracy or integrity of any portion of the work are appropriately investigated and resolved. All authors have read and approve this final manuscript.

\section{Funding}

This work is supported by the Intramural Research Program of the National Institute on Aging, National Institutes of Health (NIH), grant Z01-AG000513. AMR was supported by a summer research grant from the Kidney Disease Screening and Awareness Program. DCC is supported, in part, by grant K24 HL148181 from the National Heart, Lung and Blood Institute, NIH. The funders had no role in study design, data collection and analysis, decision to publish, or preparation of the manuscript.

\section{Availability of data and materials}

HANDLS data and code may be made available from the corresponding author upon request.

\section{Declarations}

\section{Ethics approval and consent to participate}

National Institutes of Health Institutional Review Board (\#09AGN248), approved the study protocol, as did the University of California, San Francisco Institutional Review Board (\#10-02885). All participants provided written, informed consent to participate.

\section{Consent for publication}

Not applicable.

\section{Competing interests}

The authors declare no conflicts of interest.

\section{Author details}

${ }^{1}$ College of Arts and Sciences, Cornell University, Ithaca, NY, USA. ${ }^{2}$ Division of Nephrology, Department of Medicine, Johns Hopkins University School of
Medicine, Baltimore, MD, USA. ${ }^{3}$ Center for Vulnerable Populations at Zuckerberg San Francisco General Hospital and Trauma Center, San Francisco, CA, USA. ${ }^{4}$ Department of Medicine, University of California, San Francisco, San Francisco, CA, USA. ${ }^{5}$ Laboratory of Epidemiology and Population Science National Institute on Aging, National Institutes of Health, Baltimore, MD, USA. ${ }^{6}$ Division of Nephrology, University of California, San Francisco, Zuckerberg San Francisco General Hospital and Trauma Center, 1001 Potrero Ave. Building 100, Room 342, San Francisco, CA 94110, USA.

Received: 11 May 2021 Accepted: 17 August 2021

Published online: 03 September 2021

\section{References}

1. Vanholder R, Massy Z, Argiles A, Spasovski G, Verbeke F, Lameire N. Chronic kidney disease as cause of cardiovascular morbidity and mortality. Nephrol Dial Transplant. 2005;20(6):1048-56. https://doi.org/10.1093/ndt/gfh813.

2. Rhee JJ, Zheng Y, Montez-Rath ME, Chang TI, Winkelmayer WC. Associations of Glycemic Control With CardiovascularOutcomes Among US Hemodialysis Patients With Diabetes Mellitus. J Am Heart Assoc. 2017;6(6):e005581.

3. Leon BM, Maddox TM. Diabetes and cardiovascular disease: epidemiology, biological mechanisms, treatment recommendations and future research. World J Diabetes. 2015;6(13):1246-58. https://doi.org/10.4239/wjd.v6.i13.124 6.

4. Zhou D, Xi B, Zhao M, Wang L, Veeranki SP. Uncontrolled hypertension increases risk of all-cause and cardiovascular disease mortality in US adults: the NHANES III linked mortality study. Sci Rep. 2018;8(1):9418. https://doi. org/10.1038/s41598-018-27377-2.

5. Nicholas SB, Kalantar-Zadeh K, Norris KC. Racial disparities in kidney disease outcomes. Semin Nephrol. 2013;33(5):409-15. https://doi.org/10.1016/j. semnephrol.2013.07.002.

6. Fox CS, Golden SH, Anderson C, Bray GA, Burke LE, de Boer IH, et al. Update on prevention of cardiovascular disease in adults with type 2 diabetes mellitus in light of recent evidence: a scientific statement from the American Heart Association and the American Diabetes Association. Circulation. 2015;132(8):691-718. https://doi.org/10.1161/CIR. 0000000000000230 .

7. Pickens CM, Pierannunzi C, Garvin W, Town M. Surveillance for certain health behaviors and conditions among states and selected local areas behavioral risk factor surveillance system, United States, 2015. MMWR Surveill Summ. 2018;67(9):1-90. https://doi.org/10.15585/mmwr.ss6709a1.

8. Kimmel PL, Fwu CW, Eggers PW. Segregation, income disparities, and survival in hemodialysis patients. J Am Soc Nephrol. 2013;24(2):293-301. https://doi.org/10.1681/ASN.2012070659.

9. Mujahid MS, Diez Roux AV, Cooper RC, Shea S, Williams DR. Neighborhood stressors and race/ethnic differences in hypertension prevalence (the multiethnic study of atherosclerosis). Am J Hypertens. 2011;24(2):187-93. https:// doi.org/10.1038/ajh.2010.200

10. Kershaw KN, Albrecht SS, Carnethon MR. Racial and ethnic residential segregation, the neighborhood socioeconomic environment, and obesity among blacks and Mexican Americans. Am J Epidemiol. 2013;177(4):299_ 309. https://doi.org/10.1093/aje/kws372.

11. Shaw KM, Theis KA, Self-Brown S, Roblin DW, Barker L. Chronic disease disparities by county economic status and metropolitan classification, behavioral risk factor surveillance system, 2013. Prev Chronic Dis. 2016;13: E119.

12. U.S. Department of Health and Human Services. Available at: https://health. gov/healthypeople. Accessed 26 Feb 2021.

13. Berkman LF. Social support, social networks, social cohesion and health. Soc Work Health Care. 2000;31(2):3-14. https://doi.org/10.1300/J010v31n02_02.

14. Holt-Lunstad J. Why social relationships are important for physical health: a systems approach to understanding and modifying risk and protection. Annu Rev Psychol. 2018;69(1):437-58. https://doi.org/10.1146/annurevpsych-122216-011902.

15. Brisson D. Neighborhood social cohesion: Oxford-Bibliographics in Social Work; 2014.

16. Sampson RJ, Raudenbush SW, Earls F. Neighborhoods and violent crime: a multilevel study of collective efficacy. Science. 1997;277(5328):918-24. https://doi.org/10.1126/science.277.5328.918.

17. Duncan DT, Kawachi I. Neighborhoods and health. Second edition. New York, NY: Oxford University Press; 2018. 
18. Phillips JE, Klein WM. Socioeconomic status and coronary heart disease risk: the role of social cognitive factors. Soc Personal Psychol Compass. 2010;4(9): 704-27. https://doi.org/10.1111/j.1751-9004.2010.00295.x.

19. Bot SD, Mackenbach JD, Nijpels G, Lakerveld J. Association between social network characteristics and lifestyle Behaviours in adults at risk of diabetes and cardiovascular disease. PLoS One. 2016;11(10):e0165041. https://doi. org/10.1371/journal.pone.0165041.

20. Clark NM. Management of Chronic Disease by patients. Annu Rev Public Health. 2003;24(1):289-313. https://doi.org/10.1146/annurev.publhealth.24.1 00901.141021.

21. Patterson JM, Eberly LE, Ding Y, Hargreaves M. Associations of smoking prevalence with individual and area level social cohesion. J Epidemiol Community Health. 2004;58(8):692-7. https://doi.org/10.1136/jech.2003.0091 67.

22. Fisher KJ, Li F, Michael Y, Cleveland M. Neighborhood-level influences on physical activity among older adults: a multilevel analysis. J Aging Phys Act. 2004;12(1):45-63. https://doi.org/10.1123/japa.12.1.45.

23. Cradock AL, Kawachi I, Colditz GA, Gortmaker SL, Buka SL. Neighborhood social cohesion and youth participation in physical activity in Chicago. Soc Sci Med. 2009;68(3):427-35. https://doi.org/10.1016/j.socscimed.2008.10.028.

24. Kim ES, Kawachi I. Perceived neighborhood social cohesion and preventive healthcare use. Am J Prev Med. 2017;53(2):e35-40. https://doi.org/10.1016/ j.amepre.2017.01.007

25. Audrain-McGovern J, Hughes C, Patterson F. Effecting behavior change: awareness of family history. Am J Prev Med. 2003;24(2):183-9. https://doi. org/10.1016/S0749-3797(02)00592-5.

26. Yoon PW, Scheuner MT, Peterson-Oehlke KL, Gwinn M, Faucett A, Khoury MJ. Can family history be used as a tool for public health and preventive medicine? Genet Med. 2002;4(4):304-10. https://doi.org/10.1097/00125817-2 00207000-00009

27. Clark CJ, Guo H, Lunos S, Aggarwal NT, Beck T, Evans DA, et al. Neighborhood cohesion is associated with reduced risk of stroke mortality. Stroke. 2011;42(5):1212-7. https://doi.org/10.1161/STROKEAHA.110.609164.

28. Mujahid MS, Diez Roux AV, Morenoff JD, Raghunathan TE, Cooper RS, Ni H, et al. Neighborhood characteristics and hypertension. Epidemiology. 2008; 19(4):590-8. https://doi.org/10.1097/EDE.0b013e3181772cb2.

29. Hicken MT, Katz R, Crews DC, Kramer HJ, Peralta CA. Neighborhood social context and kidney function over time: the multi-ethnic study of atherosclerosis. Am J Kidney Dis. 2019;73(5):585-95. https://doi.org/10.1053/ j.ajkd.2018.10.015.

30. Evans MK, Lepkowski JM, Powe NR, LaVeist T, Kuczmarski MF, Zonderman $A B$. Healthy aging in neighborhoods of diversity across the life span (HANDLS): overcoming barriers to implementing a longitudinal, epidemiologic, urban study of health, race, and socioeconomic status. Ethn Dis. 2010;20(3):267-75

31. Quinn TD, Wu F, Mody D, et al. Associations between neighborhood social cohesion and physical activity in the United States, National Health Interview Survey, 2017. Prev Chronic Dis. 2019;16:E163.

32. Nazmi A, Diez Roux A, Ranjit N, Seeman TE, Jenny NS. Cross-sectional and longitudinal associations of neighborhood characteristics with inflammatory markers: findings from the multi-ethnic study of atherosclerosis. Health Place. 2010;16(6):1104-12. https://doi.org/10.1016/j.healthplace.2010.07.001.

33. Tuot DS, Wong KK, Velasquez A, et al. CKD Awareness in the General Population: Performance of CKD SpecificQuestions. Kidney Med. 2019;1(2): 43-50. https://doi.org/10.1016/j.xkme.2019.01.005.

34. Baecke JA, Burema J, Frijters JE. A short questionnaire for the measurement of habitual physical activity in epidemiological studies. Am J Clin Nutr. 1982; 36(5):936-42. https://doi.org/10.1093/ajcn/36.5.936.

35. Guenther PM, Kirkpatrick SI, Reedy J, Krebs-Smith SM, Buckman DW, Dodd KW, et al. The healthy eating Index-2010 is a valid and reliable measure of diet quality according to the 2010 dietary guidelines for Americans. J Nutr. 2014;144(3):399-407. https://doi.org/10.3945/jn.113.183079.

36. Parker RM, Baker DW, Williams MV, Nurss JR. The test of functional health literacy in adults: a new instrument for measuring patients' literacy skills. J Gen Intern Med. 1995;10(10):537-41. https://doi.org/10.1007/BF02640361.

37. Lamb EJ, Stevens PE. Estimating and measuring glomerular filtration rate: methods of measurement and markers for estimation. Curr Opin Nephrol Hypertens. 2014;23(3):258-66. https://doi.org/10.1097/01.mnh.0000444813.72 626.88.

38. Inker LA, Astor BC, Fox CH, Isakova T, Lash JP, Peralta CA, et al. KDOQI US commentary on the $2012 \mathrm{KDIGO}$ clinical practice guideline for the evaluation and management of CKD. Am J Kidney Dis. 2014;63(5):713-35. https://doi.org/10.1053/j.ajkd.2014.01.416.

39. Umberson D, Crosnoe R, Reczek C. Social relationships and health behavior across life course. Annu Rev Sociol. 2010;36(1):139-57. https://doi.org/10.114 6/annurev-soc-070308-120011.

40. Bandura A. Health promotion by social cognitive means. Health Educ Behav. 2004;31(2):143-64. https://doi.org/10.1177/1090198104263660.

41. Christakis NA, Fowler JH. Social contagion theory: examining dynamic social networks and human behavior. Stat Med. 2013;32(4):556-77. https://doi. org/10.1002/sim.5408.

42. Sampson RJ. The neighborhood context of well-being. Perspect Biol Med. 2003;46(3 Suppl):S53-64. https://doi.org/10.1353/pbm.2003.0059.

43. Anderson LM, Scrimshaw SC, Fullilove MT, Fielding JE. Task force on community preventive S. the community Guide's model for linking the social environment to health. Am J Prev Med. 2003;24(3 Suppl):12-20. https://doi.org/10.1016/S0749-3797(02)00652-9.

44. Saab G, Whaley-Connell AT, McCullough PA, Bakris GL. CKD awareness in the United States: the kidney early evaluation program (KEEP). Am J Kidney Dis. 2008;52(2):382-3. https://doi.org/10.1053/j.ajkd.2008.05.026.

45. Hsiao LL, Wu J, Yeh AC, Shieh EC, Cui C, Li A, et al. The kidney disease screening and awareness program (KDSAP): a novel translatable model for increasing interest in nephrology careers. J Am Soc Nephrol. 2014;25(9): 1909-15. https://doi.org/10.1681/ASN.2013090928.

46. Mangum SA, Kraenow KR, Narducci WA. Identifying at-risk patients through community pharmacy-based hypertension and stroke prevention screening projects. J Am Pharm Assoc (Wash). 2003;43(1):50-5. https://doi.org/1 $0.1331 / 10865800360467042$.

47. Tabaei BP, Burke R, Constance A, Hare J, May-Aldrich G, Parker SA, et al. Community-based screening for diabetes in Michigan. Diabetes Care. 2003; 26(3):668-70. https://doi.org/10.2337/diacare.26.3.668.

48. Lozano P, Fleischer NL, Moore S, Shigematsu LM, Santillan EA, Thrasher JF. Does neighborhood social cohesion modify the relationship between neighborhood social norms and smoking behaviors in Mexico? Health Place. 2016;40:145-52. https://doi.org/10.1016/j.healthplace.2016.05.011.

49. Suglia SF, Shelton RC, Hsiao A, Wang YC, Rundle A, Link BG. Why the neighborhood social environment is critical in obesity prevention. J Urban Health. 2016:93(1):206-12. https://doi.org/10.1007/s11524-015-0017-6.

50. Rich MA. It depends on how you define integrated: neighborhood boundaries and racial integration in a Baltimore neighborhood. Sociol Forum. 2009;24(4):828-53. https://doi.org/10.1111/j.1573-7861.2009.01138.x

51. Thorpe RJ Jr, Brandon DT, LaVeist TA. Social context as an explanation for race disparities in hypertension: findings from the exploring health disparities in integrated communities (EHDIC) study. Soc Sci Med. 2008; 67(10):1604-11. https://doi.org/10.1016/j.socscimed.2008.07.002.

52. Cohen S. Social relationships and health. Am Psychol. 2004;59(8):676-84 https://doi.org/10.1037/0003-066X.59.8.676.

53. McNeill LH, Kreuter MW, Subramanian SV. Social environment and physical activity: a review of concepts and evidence. Soc Sci Med. 2006;63(4):101122. https://doi.org/10.1016/j.socscimed.2006.03.012.

54. Kaiser P, Diez Roux AV, Mujahid M, Carnethon M, Bertoni A, Adar SD, et al. Neighborhood environments and incident hypertension in the multi-ethnic study of atherosclerosis. Am J Epidemiol. 2016;183(11):988-97. https://doi. org/10.1093/aje/kwv296.

55. Christine PJ, Auchincloss AH, Bertoni AG, Carnethon MR, Sánchez BN, Moore $\mathrm{K}$, et al. Longitudinal associations between neighborhood physical and social environments and incident type 2 diabetes mellitus: the multi-ethnic study of atherosclerosis (MESA). JAMA Intern Med. 2015;175(8):1311-20. https://doi.org/10.1001/jamainternmed.2015.2691.

56. McCullagh MC, Rosemberg MA. Social desirability Bias in Self-reporting of hearing protector use among farm operators. Ann Occup Hyg. 2015;59(9): 1200-7. https://doi.org/10.1093/annhyg/mev046.

\section{Publisher's Note}

Springer Nature remains neutral with regard to jurisdictional claims in published maps and institutional affiliations. 